\title{
DESIGN STUDENTS' TAKE ON CO-DESIGN IN HEALTH: REFLECTIONS FROM LEARNING AND EDUCATION PERSPECTIVES
}

\author{
Høiseth, Marikken; \\ Forshaug, Ann Kristin \\ Norwegian University of Science and Technology
}

\begin{abstract}
Using three projects as a showcase, the aim of this article is to report on design students' take on codesign in health, in terms of both outcomes and processes. It builds on project work conducted in a master's course called 'Design for Society', reserved for 4th-year industrial design students in the Department of Design at the Norwegian University of Science and Technology. The students were encouraged to explore how healthcare services could facilitate active, informed and involved patients. The overall theme was provided by a cluster funded by the Norwegian Research Council addressing co-creative service design and innovation in health. Based on initial research, the students, organised in groups, identified a chronic illness that has a lifelong impact on everyday life, such as cystic fibrosis, fibromyalgia, and Alzheimer's disease. We give an account of three selected projects by showcasing developed concepts, central methods and tools, and we share key reflections from the students and the course educators on their experiences of working with co-design in health in an academic environment.
\end{abstract}

Keywords: Collaborative design, Design education, Design process, co-design, active patients

\section{Contact:}

Høiseth, Marikken

Norwegian University of Science and Technology

Department of Design

Norway

marikken.hoiseth@ntnu.no

Cite this article: Høiseth, M., Forshaug, A. K. (2021) 'Design Students' Take on Co-Design in Health: Reflections From Learning and Education Perspectives', in Proceedings of the International Conference on Engineering Design (ICED21), Gothenburg, Sweden, 16-20 August 2021. DOI:10.1017/pds.2021.108 


\section{INTRODUCTION}

Design, and notably service design, is increasingly recognised as a discipline that can add value to the development and innovation of healthcare services (Pfannstiel and Rasche, 2019). Significant challenges that are expected on a global level in the near future include increased life expectancy, a growing number of people living with chronic diseases and more people developing dementia, and they progress alongside other widespread social trends such as globalized economies, geographic centralisation and rapid evolvement of technology (Beard and Suzman, 2011). Recognising change to be a multilevel and multifaceted phenomenon, responses to the abovementioned challenges will take various forms and come from different directions (Kuipers et al., 2014). Within the Cluster for Cocreative Service Design and Innovation (CCSDI), we have identified facilitating active, informed and involved patients as one such significant response. In the fall of 2018, we invited our 4th-year industrial design students at the Norwegian University of Science and Technology (NTNU) to explore how healthcare services could facilitate active, informed and involved patients. Following Ho, Ma, and Lee (2011), we direct attention towards novice designers and acknowledge the importance of their take on and experience with co-design practice as they set the tone for the future design scenery. Unlike professional consultancy projects, design students often approach their work with a certain independence and idealism, which brings noteworthy perspectives and proposals to the table (Blindref, 2019). Reflections of designers' experiences with participatory approaches is useful input for educators and practitioners seeking to develop improved design processes (Stam and Boon, 2018).

The aim of this article is to report on design students' take on co-design in health by using three projects as a showcase of their processes and outcomes. This introduction will continue to give a short background of the specific design course called 'Design for Society' and CCSDI. Next, we give an account of the projects in terms of the developed concepts, central methods and tools. Then, we share reflections from the students on their experiences of working with co-design in health. Finally, we provide some reflections from our perspective, as course educators, on teaching for the field of co-design in health. Our paper helps to broaden the limited literature on teaching and learning participatory design and co-design as part of an academic curriculum (Christiansson, Grönvall and Yndigegn, 2018; Hecht and Maass, 2008; Simonsen, Malik, From, Parslov and Sørensen, 2020).

\subsection{The 'Design for Society' course}

'Design for Society' was a master's course aimed at using co-design and participatory methods, tools and theory for exploring societal issues and contribute to positive change (Høiseth, 2019). An overall goal was to develop critical thinking about the designer's role in society, including reflection and reflexivity. The students were encouraged to use design methods that inspire active participation to develop new and value-creating products and services that benefit society as a whole.

The students worked in groups of 4-5 members, and we recommended they follow IDEO's design process, which includes three phases: 'hear', 'create' and 'deliver' (IDEO, 2011). As far as possible, collaboration and co-design with relevant actors and end users throughout the process was pursued. The projects in this course corresponded to 'live' projects that are "set up in real-world settings with real stakeholders, and with participants with a real stake in the issue of design" yet "designed to allow for a fruitful learning situation, differentiating them from larger 'real' projects" (Christiansson, Grönvall and Yndigegn, 2018, p. 1). Moreover, the students were expected to integrate theory from the curriculum, use recommended toolkits and supplement with existing research that was relevant to their specific project. Following the account of Sanders and Stappers (2014), we take co-design to be a process wherein professional designers work together with actors, who represent other backgrounds and competencies, to explore and create solutions jointly. Here, the use of probes, generative toolkits and prototypes is common to support people as makers in the design process. A co-design approach contributes to representing and ensuring input from various disciplines, perspectives and experiences. Within the health sector, co-designers typically include actors such as healthcare professionals, service providers, healthcare users, patients, residents, family members or authorities.

In the 'hear' phase, the students had to select a target group by identifying a chronic illness with a lifelong impact on everyday life. This work was to be based on insights and patient stories published and readily available, for example via blogs, vlogs, podcasts and documentaries, combined with qualitative studies and established contact with a relevant patient organisation. Furthermore, they had 
to propose and conduct a set of co-design methods to provide deeper understanding, empathy and ethical reflection. In the 'create' phase, the students were to process this insight by analysing, finding patterns and prioritising categories. Along the way, they worked out concept proposals to meet the prioritised insight. The proposals had to promote positive aspects of active, informed and involved patients and could be manifested as a product, a service or an information system. Within this course, coming up with relevant concepts that acknowledge real needs clearly implied involving stakeholders and end users as early and as much as possible. In the 'deliver' phase, the students continued with iterations to improve and detail their proposal based on collaboration and co-design with central actors and end users. The final delivery consisted of a concept proposal and a report that documented the process, important findings and the proposal, in addition to reflections on how the proposal met the goal and how they experienced the process as a whole.

\subsection{The cluster}

NTNU is a partner in the CCSDI (ccsdi.no). The cluster's aim is to develop new knowledge on methods, tools and mindsets for co-creative service design as an approach to service innovation in healthcare. There are currently 16 partners representing primary and specialist healthcare, the service design sector, service users, patient organisations and academia by researchers and professionals from service design, information and communications technology, technology management, nursing science and medicine. An initial mapping of the cluster's internal interests and challenges led to the identification of central topics, one of which is the need to facilitate active, informed and involved patients. The hypothesis is that active participation contributes to improved services. First of all, because patients know how they like to live their everyday lives, they are well qualified to anticipate how potential contact with healthcare personnel, medication or treatment could fit within their lives. As such, increased involvement might lead to more efficient treatment and care and in turn contribute to more sustainable health systems concerning resources and economy. Second, empowered patients are expected to have better patient and health experiences. Third, just as there has been a paradigm shift in design from 'designing for' to 'designing with', a similar paradigm shift has taken place in healthcare - from paternalistic models where health personnel take most decisions to a collaborative relationship wherein solutions are increasingly figured out together (Vis, 2018).

\section{PROJECTS}

Here we present three of the projects by showcasing the developed concepts, central methods and tools. The selected projects address cystic fibrosis, fibromyalgia and Alzheimer's disease.

\subsection{Project 1: Cystic Fibrosis - Story Bloqs}

How can you explain to someone that you have a chronic and incurable disease but that you are also an ordinary person? This question, posed by a young man with cystic fibrosis (CF) whom the students interviewed, became the starting point for this group (Gulliksrud, Kaland, Laverty, and Ramstad, 2018). CF is a congenital and genetic disease causing the mucus-producing glands in the body to secrete overly thick mucus, affecting the lungs, pancreas and gastrointestinal tract (Cystisk fibrose, 2016). The students interviewed three patient peers, amongst others, and became familiar with their different stories and experiences. Through analysis, they found that getting to know, share and learn from stories of people with CF was of collective interest.

The group continued to work on storytelling as an idea, envisioning a communication tool that facilitates storytelling to promote active, informed and involved patients. Inspired by the modularity and flexibility of children's building blocks, they used a set of coloured blocks and keywords representing elements of a story as prototyping material (Figure 1a). These blocks were used to further co-design with invited patient peers to ensure relevance and suitability. During sessions with the codesigners, the blocks were identified as a useful tool to help initiate conversations with different purposes - explaining their illness, sharing experiences and educating relatives and friends through storytelling. 

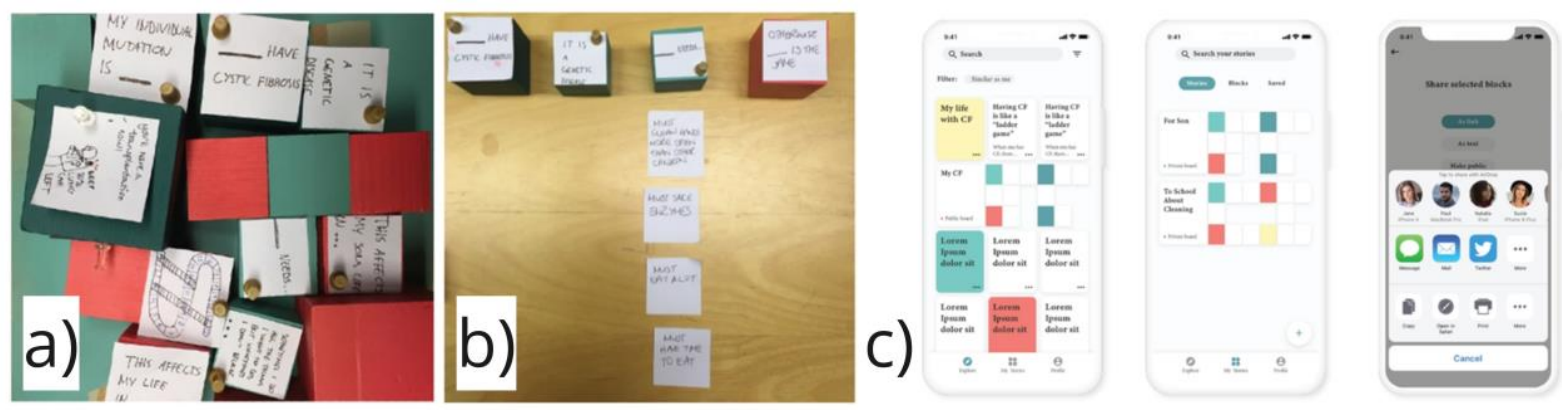

Figure 1a) Coloured blocks as prototyping material; b) storyboard for birthday party; c) The 'Story Bloqs' app. Source: Gulliksrud, Kaland, Laverty, and Ramstad, 2018.

Figure $1 \mathrm{~b}$ shows a co-designer's layout of the prototyping blocks, which are considered important in a particular situation of a child with CF attending a new friend's birthday party (storyboard). As other blocks will be important in communication with the school or regarding leisure activities, the setup can be expanded and changed accordingly for adaptation to a given situation. Other situations that codesigners deemed relevant were public workout sessions and making new acquaintances.

The final concept proposal was the app 'Story Bloqs' (Figure 1c), which provides new opportunities for tailored storytelling about one's own illness by creating and sharing snippets of stories as well as browsing stories from others facing similar conditions. In the app, you build a story by creating small story sections (blocks) and combining them into a so-called storyboard to convey a meaningful story or information intended for a specific recipient. Besides making storyboards to understand personal thoughts, they can be shared with others so that anyone interested can use, learn or be inspired by your storyboard or blocks.

Story Bloqs facilitates adaptation of one's story to a specific situation or context. The system is designed so that people with CF can choose the ways in which they want to relate to others by sharing a story or a piece of information. Sometimes it might be a matter of objective information sharing, while in other cases, one might want to be more personal. Information or experiences can easily be shared without needing to meet face to face. As one of the co-designers who represented patients expressed it, 'This would be a gift for more private, less outgoing persons with CF' (Gulliksrud, Kaland, Laverty, and Ramstad, 2018, p. 43). As such, the app can contribute to increased knowledge and understanding from the community. One is free to include anything that fits a particular situation, which in turn stimulates personal and others' reflection. This can result in viewing people with CF more holistically.

\subsection{Project 2: Fibromyalgia - FIBRO Progress Journal}

One group (Bjørnå, de Smit, Haugen, Hutcheson, and Malcolm, 2018) worked with the disease fibromyalgia by asking, How can co-creation be used as a tool to improve the quality of life of people living with fibromyalgia? Fibromyalgia is a chronic pain condition with an unknown cause affecting connective tissue, muscles, ligaments and tendons (Fibromyalgi, 2017). To achieve insight and gain empathy, the students combined semi-structured interviews, storytelling and storyboarding (Hanington and Martin, 2012) in co-creation with patients. The students set out to learn more about the symptoms of the disease, the process of being diagnosed and how the disease can affect patients' everyday lives and social relationships. They found that a major challenge facing people who are diagnosed with fibromyalgia is to accept the disease as chronic and to adapt to a new lifestyle with a positive attitude. Their research revealed that depression and anxiety are common among the patients, conditions that are also related to increased experience of pain and tiredness. They also found that guidance on how to deal with the disease and master pain, the experience of helplessness and negative thoughts was lacking. Based on this, they identified the time span after being diagnosed to be important in creating a foundation for personal awareness, adaptation to a new lifestyle and acceptance. 
The students developed a concept called 'Embrace' (Figure 2a). The idea was to make a tool for young, newly diagnosed patients with fibromyalgia to adjust to their new life by promoting a mindset that can help them transform negative emotions associated with pain into hope, motivation and overall acceptance.
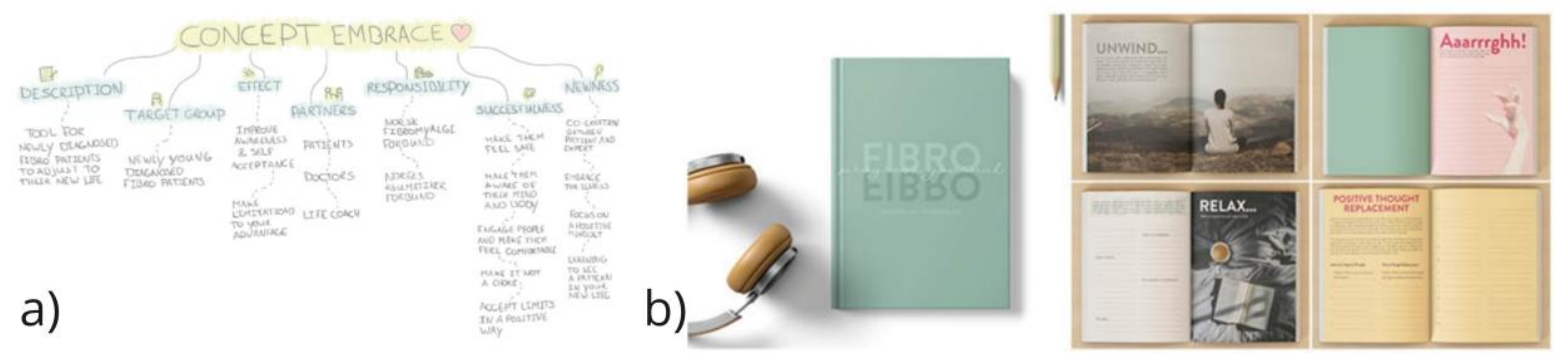

Figure 2a). Pillars of the 'Embrace' concept; b) The 'FIBRO progress journal'. Source:

Bjørnå, de Smit, Haugen, Hutcheson, and Malcolm, 2018.

To concretise how the tool could realise such a transformation, the students determined the intended impact of the concept and actions that could lead to it. Eventually the format of the toolkit as a small diary was chosen wherein various activities to promote a positive mindset would be suggested. Next, some significant touchpoints were determined. The patients should receive the tool from their GP at the time of diagnosis. This way, the patients immediately get something to hold on to, and involving the GP might spark a particular motivation to use it. The patients can use the tool at home on a regular basis for a certain period, alone in quiet surroundings. Its small size makes is easy to bring along if patients prefer it. The patients can interact with the tool through reading, reflecting, writing and drawing, and an anticipated motivational factor is how the diary provides concentrated access to reflection. Reflecting on everyday thoughts and activities can foster a positive mindset and acceptance of their disease.

The final concept proposal is a book called the 'FIBRO progress journal' intended to be used during the first months after diagnosis (Figure 2b). The aim of the book is to help young patients with fibromyalgia to master everyday life and promote a positive mindset. It is primarily intended as a tool for the patients themselves; however, it could also be valuable to use in agreement with their GP or psychologist. It contains a number of exercises that were selected to encourage reflective thinking, a positive mindset and physical activity. Similar to a design probe, the book invites active participation and co-creation in that the patients can continue from where the designers left off. The students carefully chose pictures accompanied with a light or sometimes defiant verbal tone, as well as some gentle instructions to inspire activities such as unwinding, releasing frustration and positive thought replacement.

\subsection{Project 3: Alzheimer's Disease - The Melody of Memories}

The group addressing Alzheimer's disease (Bjørgum, Glesaaen, Goosink, and Jacobsen, 2018) based their choice on the high occurrence of this specific dementia type and the abundant amount of online information. Alzheimer's disease is an irreversible, progressive disease with dementia symptoms of memory loss ranging from mild in its early stages to severe in the late stages (Alzheimers sykdom, 2015). To obtain rich insights, the group combined qualitative methods such as analysing a series of self-portraits documenting the gradual mind decay of an artist with Alzheimer's disease, expert interviews, guided tours and participatory observations in nursing homes.

The students learned that patients living in a nursing home are mainly in the last stage of dementia. A common factor is their complete dependence on others to manage everyday life because of severe memory problems, loss of muscular control and weakened ability to converse (Alzheimers sykdom, 2015). At this stage, the priority is to create safe and trusted routines; familiarize with the patients' preferences in food, clothing and entertainment; engage in thoughtful communication; provide music and art experiences; emphasise the 'here and now' and facilitate achievement. This helps to enhance the patients' perceptions of comfort and meaningfulness. Time and human contact were found to be two essential yet scarce components.

Analysis revealed music to be a recurring factor. Music can lead to strong, emotional experiences. The students referred to an important episode during one of their participatory exercises. As they were done talking to one of the staff members, she suddenly came running back up the stairs exclaiming, 'Music! People without language can sing a whole song!' 
The students gained interviewed a nurse specialised in music for dementia patients. According to her, music is a limitless remedy - calming down even patients expressing restless or aggressive behaviour straightaway. Songs from patients' childhoods are often still in their memories. Most patients, however, are completely dependent on the staff to play the music. A user study was conducted to explore dementia patients' experiences with feeling different tactile objects (Figure 5a). Eight material samples were explored and received diverse responses - smiles, curiosity, dislike and articulated childhood memories. Another user study involved a prototype consisting of a Bluetooth speaker set to play a traditional folk song and wrapped in a knitted cover with a classical Norwegian pattern. The patients were given the gently vibrating speaker to hold while listening (Figure 5b). The patients showed a particular interest in the experience; some sang along, and others held it close to their ears. The pattern was recognised and appreciated. The students concluded music to be favourable in that it made the patients light up, actively sing along and generally appear very content. The tangible aspects seemed to make it easier to connect with the music.
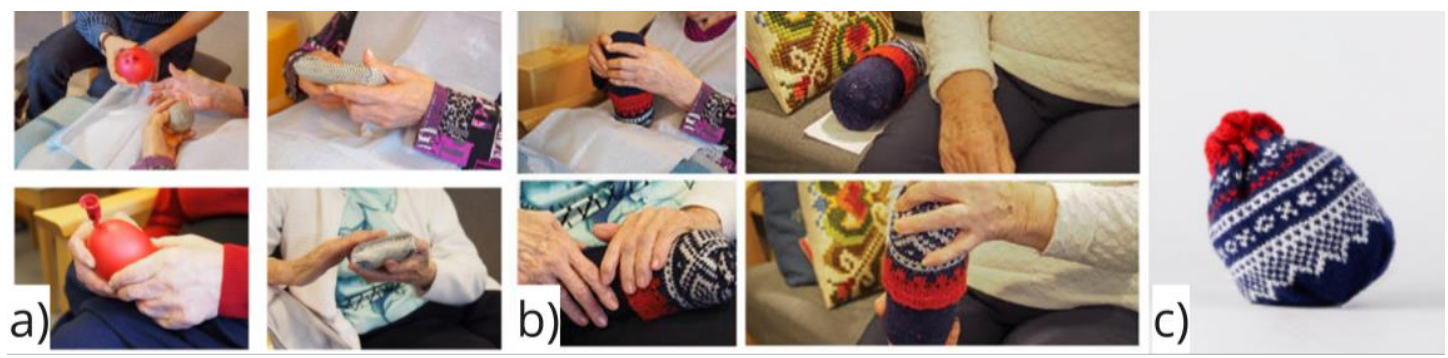

Figure 5a) Exploring experiences with different tactile objects; Exploring a tangible musical experience; c) The Egg. Source: Bjorgum, Glesaaen, Goosink, and Jacobsen, 2018.

A final prototype revision included reducing its weight and size, leading to the product named The Egg, as shown in Figure 5c. By bringing the music into the patient's immediate presence and limiting the time frame to one song to create a special moment, the students hoped to evoke the involvement of patients with Alzheimer's disease. The Egg should combine the 'here and now' with music and tactility - addressing the significance of feeling instant joy realised through music. The goal is to facilitate experiencing music together, among patients or between patient and nurse, seeing it as basic human interaction - purely connecting in one another's presence (Bjørgum et al., 2018).

\section{SOME KEY REFLECTIONS FROM THE STUDENTS}

The reflections that we refer to here are taken from the student reports. A reflection that was brought up by all three groups was the difficulty in gaining access to end-user representatives for co-design sessions. An important reason was ascribed to the health characteristics of the assignment, addressing patients in particular. Another reason that was mentioned was the difficulty of explaining the content and outcome of the co-design session because broad room for idea generation is typically preferred. One group attempted to clarify by making visuals to explain the research and how they wanted to include people as co-designers. Setting up conventional meetings with professionals, however, was found to be easier to implement than with patients. The students working with Alzheimer's disease had success with requesting nurses to be in charge of establishing further contact between students and patients. However, the nature of the disease prevented reflective conversations with the patients, leading the group to rely more on the experiences of the staff. According to the students, this might have led to needs not being appropriately understood or even overlooked. As an attempt to compensate, the students reasoned that it was important to include more staff and visit more nursing homes. The group working with fibromyalgia had limited opportunities for co-design due to lack of contact with users:

The lack of contact with stakeholders delayed our process considerably, and we felt 'stuck in a box' without knowing what the next step should be. We asked ourselves many questions concerning why they would not respond. Was there anything wrong with how we presented ourselves? Would they not see our work as a serious enough project? How often could we issue reminders for a response without being annoying and intrusive? (Bjørnå et al., 2018, p. 37) 
At the same time, this led to their discovery of alternative methods of co-creation, such as engaging in role play in a way that enabled gaining empathy with patients and kept them at the centre of the design process: 'The insights gained allowed us to consider the struggles of the Fibro patients during our role play to allow relevant feedback to be obtained and iterations to be made' (Bjørnå et al., 2018, pg. 98). For the group working with CF, it also proved difficult to gain direct access to patients. However, and similarly to the other group, turning to personal empathy was powerful. An alternative approach was found in triangulation combined with high awareness of subjective lifeworlds: 'We have also worked with a diverse triangulation of users. Even though all the users have CF, the illness affects them very differently and they are all in very different situations', and 'When we could not understand their feelings around the telling of stories, we tried to do it ourselves to see how we would feel' (Gulliksrud et al. 2018, pg. 64). Some of the groups eventually got access to a few patients by reaching out to their own personal network. Related to empathy, one of the groups provided a profound reflection on how they were touched during user testing:

Unexpectedly, the music also had [an] effect on us as researchers. Where the testing up to the point of playing music felt a bit mechanical, listening to music with the patients felt more intimate and special. It was impossible for the sudden happiness of patients to not affect us. We connected with patients a lot better after this test. (Bjørgum et al., 2018, pg. 69)

The course also emphasises ethics, and all the groups have to start working on a code of conduct from the very beginning. The lectures about ethics cover ethics in data creation, handling and storage, using the principles of respect, responsibility and honesty as pillars (IDEO 2015). Acknowledging the importance of ethics, the students reflect upon situations that did not resonate with their own code of ethics. For example, during user testing of the group addressing Alzheimer's disease, one of the nurses decided to wake up a sleeping patient. Providing a description of a patient looking confused and unwilling to participate in the exploration of tactile objects, the students revealed, 'It was difficult for us to observe how it seemed like the patient, in that moment, was robbed of their own free will' ((Bjørgum et al., 2018, pg. 75). They continued to reflect,

We still felt that the moment when the woman was forced to help us, was a tiny window into many Alzheimer's patients everyday life. How they might not be able to communicate what they want and how sometimes their efforts might be lost on someone who doesn't have the time or is not that interested in listening. (Bjørgum et al., 2018, pg. 76)

Another aspect that the students addressed has to do with the specific student composition within the course, combining students attending the 5-year MA program with students from the international 2year MA program and exchange students. Given that the most accessible site for fieldwork is local and hence Norwegian, the students did experience language barriers, leading to unfortunate circumstances. Some argued that their ability to conduct effective co-creation was somewhat hampered due to a mix of different languages within the student group.

All of the groups revealed a genuine conviction of the importance of co-design, explaining how its strength is to enable a variety of users and stakeholders to take part as designers so that different perspectives related to a problem are highlighted. Understanding the role of contemporary designers to be similar to that of a mediator, methods and tools that support people to express themselves and communicate are seen as a condition to keep people at the centre of research and hence design. For instance, making blocks and using them to act as boundary objects (Hanington and Martin 2012) in co-design was considered a success: 'We spent a lot of time working with the blocks to find out how they best could assist us in the co-designing sessions, and we would want to use it again in another project when appropriate' (Gulliksrud et al. 2018, pg. 64). Moreover, the students emphasised the responsibility to remain sensitive and open-minded so that co-designers can feel comfortable and trust that their information and contributions are being treated with respect and honesty. Essentially, listening is seen as one of the most important activities for a designer. In this context, the importance of integrating critical thinking and being aware of different world views is recognised. The students generally concluded that more time to co-design and develop the concept through iterations is a necessity for further progress. Finally, there seems to be a deliberate awareness of the role of technology. While seeing the importance of being able to adapt to novel technology, the students 
sensibly asserted that 'it's vital that not all problems need technology in order to have a solution' (Bjørgum et al., 2018, pg. 77).

\section{SOME KEY REFLECTIONS FROM THE COURSE EDUCATORS}

Difficulties gaining access to end users in healthcare projects is known as a threshold for both professionals and students. Nevertheless, the student groups managed to contact and recruit end users throughout the projects. Our impression is that letting the groups make an active choice of user groups led to increased motivation and engagement among the students. This is in line with underlying theories of constructivist, co-constructivist and problem-based learning on which teaching practices in participatory design and co-design is typically based on (Andrews et al., 2014). As pointed out by Andrews et al. (2014) there is great pedagogical value in supporting students to be active learners through offering educational experiences that requires them to construct their own "models" of a situation, deciding how to approach it, expressing reasons for their choices, articulating what they think now and consequently being able to choose to think differently. This process often includes both experiences of "feeling lost" and eventually "finding a way" to foster participation with the available resources (Andrews et al., 2014). However, our choice of letting students be in charge of recruiting also resulted in a variation of involvement of end users among the groups. Although some of the groups successfully managed to support end users to take the role as co-designers in co-creation workshops, others were in less direct contact with the users and as such did not experience the same opportunities to meet the purpose of this course: to familiarise students with co-design and participatory methods. Even if students have difficulties recruiting participants, Christiansson, Grönvall and Yndigegn (2018) emphasize the importance of working with people that have a potential stake in the particular topic to experience participatory design to the full extent and therefore require their students to establish collaboration with true stakeholders. Acknowledging existing limitations due to both the academic setting and uncertain factors that are particularly true in healthcare projects prompts us to consider integrating smaller initial assignments that ensure some basic experience with co-design and participatory methods to improve the course. Here we can be inspired by the Co-design course of Christiansson, Grönvall and Yndigegn (2018, pg. 4) which started with "a 2-week 'rapid Codesign' project in 'safe' environments to introduce fundamental perspectives, methods and tools". Moreover, while we agree that live projects provide the best learning opportunities for participatory design (Christiansson, Grönvall and Yndigegn, 2018), continuing to explore how blogs, vlogs, podcasts, documentaries and literature can be a rich source for gained empathy and critical thinking will be given priority. This can be especially valuable in health-related projects given particular challenges with recruiting patients and healthcare staff. We see the need for more guidance and targeted assignments to succeed in realizing more of the potential within these sources.

The students' experienced difficulty of explaining the content and outcome of co-design work. Christiansson, Grönvall and Yndigegn (2018, pg. 6) confirm this, recognizing that "When students approach a potential user group, a fundamental and unavoidable challenge is that the live project is a hard sell; it is difficult for the students to offer the users incentives to participate". From a student perspective, Stam and Boon (2018) suggest that design students would benefit from the specific qualities of courage, social sensitivity and responsiveness to facilitate participatory design processes. We understand this as a complex tension in which design students need to convey and convince others about their own contributions as designers while at the same time being fully aware and respectful of others' domain knowledge in line with participatory principles. To address this tension, it would be interesting to further explore how we could equip students with the approach of employing visuals or tangibles from the very beginning for clarifying and substantiate their intentions and their ways of working for both themselves and others such as gatekeepers and end-users.

An overall goal of the course was to develop critical thinking about the designer's role in society, including reflection and reflexivity. One of the groups approached their insight work through the use of autoethnography, i.e., an ethnography in which the author acts as both investigator and informant (Cunningham and Jones, 2005). The group members did not only describe their observations from their field work but used their own reactions and feelings of meeting the people in the context to increase their understandings. By showing the thoughts and reactions of each group member through a text written by each individual, they also managed to share and reflect upon how different people would understand the same observation differently. It is our understanding that the autoethnographic 
approach increased the group's sensitivity to the users and their ability to differ between their own thoughts and ideas and the actual needs of the people living with these illnesses:

The woman had speech, so that was no issue. The silence made me a little uncomfortable, which surprised me. I tried keeping up the dynamic in the conversation, but quickly felt alone in the attempt. (Bjørgum et al., 2018, pg, 22)

To foster reflexivity, all groups were initially asked to do a preliminary mapping (Visser, Stappers, Van der Lugt and Sanders, 2005), where they explicitly described their preunderstanding of the topic. An example of reviewing such a first assumption was provided as follows, 'However, communicating how you felt to doctors, friends and family was not as challenging as we first assumed' (Bjørnå et al., 2018, p. 42).

Interestingly, the groups provided few, if any, direct accounts about stakeholders' experiences of participating as co-designers. In future courses we will seek to increase awareness of the co-designers' experiences in participatory work by offering specific exercises and encouraging use of evaluation tools currently under development by the CCSDI for addressing different dimensions of co-creative processes.

The end results varied, and each group ended up with unique and interesting outcomes. At least two of the presented projects appear to be rather low-cost solutions, and several of the groups encouraged the involved actors to continue with further work on their projects. In our opinion, the solutions and the processes that led to them are important contributions to facilitate more active, informed and involved patients. Both the 'FIBRO progress journal' and the 'Story Bloqs' app can be understood more as frameworks rather than a fixed solution. As such, their value in use is realized when the patient develops them further on their own. The Egg presents music and tactile qualities to evoke cherished memories which could help patients to be involved and engaged even if only in a dedicated moment.

Given that the students' backgrounds and specialisations are quite diverse, mainly because the course is mandatory for students from two different study programs, as well as open to affiliated study programs and exchange students, the initial knowledge about the mindsets, methods and tools of codesign and participatory methods varies among the students. The different projects revealed considerable variation in terms of topics and process, and the students put a lot of effort into finding appropriate ways of working. A mixture of classroom lectures, workshops and group supervision has been used as a teaching method. The latter in particular has made it possible to give groups tailored feedback and supervision. As is the case with professional projects, it is hard to find one single way of working with co-design and participatory methods; hence, we find it essential that the students acquire knowledge and experience through the process of finding appropriate methods and applying them in the relevant context.

\section{CONCLUSIONS}

In this article, we presented three projects carried out by design students exploring how healthcare services could facilitate active, informed and involved patients. The projects were described in terms of developed outcomes as well as applied methods and tools to achieve collaboration and co-design with central actors and end users. Moreover, we shared some reflections on experiences of working with co-design in health from both the students' viewpoints and our own perspectives as course educators. Showcasing these projects is expected to contribute with knowledge about how novice designers go about co-design and its practice as well as aspects to consider when teaching participatory design. This should be of interest and value to the design community in general and in particular to course educators in academia who are concerned with health-related co-design.

\section{ACKNOWLEDGMENTS}

Thank you to all the devoted design students who participated in the 'Design for Society' course in autumn 2018; to the external actors and associated co-designers; and to CCSDI, who contributed with their valuable effort, time and attitudes. This work was supported by Research Council of Norway, HELSEVEL, project number: 269456. 


\section{REFERENCES}

Alzheimers sykdom. (2015), Retrieved April 4th 2019 from https://helsenorge.no/sykdom/hjerne-og-nerver/ demens/demenssykdommer

Andrews, B., Bardzell, S., Clement, A., D'Andrea, V., Hakken, D., Poderi, G., ... \& Teli, M. (2014). Teaching participatory design. In Proceedings of the 13th Participatory Design Conference: Short Papers, Industry Cases, Workshop Descriptions, Doctoral Consortium papers, and Keynote abstracts-Volume 2 (pp. 203-204).

Beard, John, and Richard Suzman. (2011), "Global health and aging”. US Department of Health and Human Services: National Institute on Aging, 2-15. NIH Publication no. 11-7737.

Bjørgum, Ida, Peter Kristian Glesaaen, Bram Goosink, and Live Jacobsen. (2018), The melody of memories. Final report in the course TPD4156 - Design for Society. Unpublished manuscript, Norwegian University of Science and Technology, Trondheim.

Bjørnå, Sofie, Merel Kayalla de Smit, Ylva Nagelhus Haugen, Roanna Hutcheson, and Paul Stanley Malcolm. (2018), Design for health. Facilitating for active, informed and involved patients of Fibromyalgia. Final report in the course TPD4156 - Design for Society. Unpublished manuscript, Norwegian University of Science and Technology, Trondheim.

Christiansson, J., Grönvall, E., \& Yndigegn, S. L. (2018, August). Teaching participatory design using live projects: critical reflections and lessons learnt. In Proceedings of the 15th Participatory Design Conference: Full Papers-Volume 1 (pp. 1-11).

Cunningham, S. J., \& Jones, M. (2005). Autoethnography: a tool for practice and education. In Proceedings of the 6th ACM SIGCHI New Zealand chapter's international conference on Computer-human interaction: making CHI natural (pp. 1-8).

Cystisk fibrose. (2016), Retrieved April 2nd 2019 from https://helsenorge.no/sykdom/sjeldne-diagnoser/cystiskfibrose

Fibromyalgi. (2017), Retrieved April 2nd 2019 from https://helsenorge.no/sykdom/muskel-og-skjelett/ fibromyalgi

Gulliksrud, Siri Margrethe., Thomas Colin Guo Kaland, Maureen Selina Laverty, and Idun Sarre Ramstad. (2018), Cystic Fibrosis. Facilitating for storytelling. Final report in the course TPD4156 - Design for Society. Unpublished manuscript, Norwegian University of Science and Technology, Trondheim.

Hanington, Bruce, and Bella Martin. (2012), Universal methods of design: 100 ways to research complex problems, develop innovative ideas, and design effective solutions. Beverly: Rockport Publishers.

Hecht, K. M., \& Maass, S. (2008). Teaching participatory design. In PDC (pp. 166-169).

Ho, Denny Kwok-leung, Jin Ma, and Yanki Lee. (2011), "Empathy@ design research: a phenomenological study on young people experiencing participatory design for social inclusion.” CoDesign 7(2): 95-106. https://dx.doi.org/10.1080/15710882.2011.609893

Blindref. (2019)

IDEO. (2011), Human centered design toolkit. 2nd ed. Creative Commons Attribution. Retrieved March 2, 2018, from http://www.designkit.org/

IDEO. (2015), The Little Book of Design Research Ethics. 1st ed. Creative Commons Attribution. Retrieved March 2, 2018, from https://lbodre.ideo.com/download/

Kuipers, Ben S., Malcolm Higgs, Walter Kickert, Lars Tummers, Jolien Grandia, and Joris Van der Voet. (2014), "The management of change in public organizations: A literature review." Public administration 92(1): 1-20. https://dx.doi.org/10.1111/padm.12040

Multippel sklerose. (2017), Retrieved April 4th 2019 from https://helsenorge.no/sykdom/hjerne-ognerver/multippel-sklerose-(ms)

Pfannstiel, Mario A., and Christoph Rasche, eds. (2019), Service Design and Service Thinking in Healthcare and Hospital Management. Cham: Springer International Publishing.

Sanders, Elizabeth B-N., and Pieter Jan Stappers. (2008), "Co-creation and the new landscapes of design." Codesign 4(1): 5-18. https://dx.doi.org/10.1080/15710880701875068

Simonsen, J., Zahoor Malik, A., From, G., Filippson Parslov, M., \& Tue Sørensen, L. (2020). A Checklist For A Successful PD Student Project. In Proceedings of the 16th Participatory Design Conference 2020Participation (s) Otherwise-Volume 2 (pp. 119-123).

Stam, D., \& Boon, B. (2018). What you gain and what it takes: a student's reflection on a participatory design project. In Proceedings of the 15th Participatory Design Conference: Short Papers, Situated Actions, Workshops and Tutorial-Volume 2 (pp. 1-5).

Vis, Anne Carlijn. (2018), Matching Intentions with Experience: A human-centred service design approach to shared decision making. (Unpublished doctoral dissertation). Norwegian University of Science and Technology, Trondheim.

Visser, F. S., Stappers, P. J., Van der Lugt, R., \& Sanders, E. B. (2005). Contextmapping: experiences from practice. CoDesign, 1(2), 119-149. 